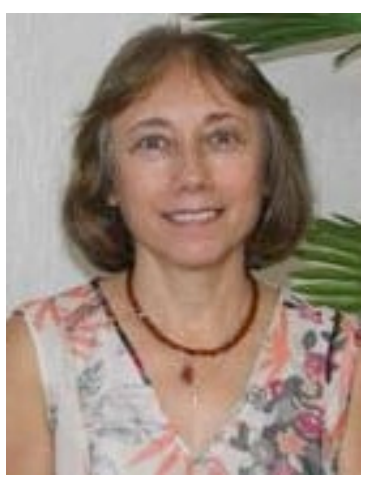

\title{
A saúde mental dos indivíduos na atualidade
}

Na elaboração deste editorial, houve a necessidade de encontrar um ponto comum entre os vários artigos que compõem o fascículo, pois os temas são diversos. Passam por doenças clínicas como o enfrentamento do câncer com estratégias religioso/ espirituais, a vivência de ser doente com AIDS e os simbolismos associados à doença e expressos em grupo (isolamento e exclusão social), incluem as considerações sobre o vínculo entre mães usuárias de drogas e seus filhos, e sobre a inserção familiar no tratamento da fobia social. Também são abordados temas que se situam no contexto da atenção primária, como a perspectiva dos profissionais que atuam nesse nível, sobre a abordagem de usuários de crack, além da presença de possíveis indícios de sintomatologia depressiva entre os enfermeiros da atenção básica, e, como possível extensão do trabalho de prevenir o consumo de álcool, o estudo da identificação dos fatores pessoais (sexo e idade), que parecem influenciar o uso dessa substância entre adolescentes estudantes. Um possível ponto em comum de todos os artigos seria as pessoas e os vínculos que elas estabelecem na vida. Essa escolha permite fazer uma reflexão interessante sobre o ser humano, o seu contexto e as suas relações, bem como as formas que encontra para gerenciar os desconfortos psíquicos no mundo atual.

A respeito da presente fase da humanidade, Bauman ${ }^{(1)}$ sociólogo da década de cinquenta, (professor universitário, aposentado nos anos noventa, com vasta produção), discorre sobre as características do que denomina "Modernidade líquida". A modernidade líquida é um tempo de incertezas, no qual os indivíduos encontram-se em uma condição de obrigação de serem livres de fato, com um desenho de vida semelhante a um "menu de opções" onde cada um seria o autor do seu script. Porém, a outra face da liberdade é a responsabilidade, a capacidade de fazer escolhas, características que tornam o ser humano um ser moral, moralidade que é consubstancial ao homem (não um produto social) e atrelada à ambivalência, como uma condição inevitável da existência humana.

Essa visão aparentemente positiva, é na realidade uma miragem do que efetivamente se supõe, dado que a cultura da flexibilidade tende a destruir qualquer previsão de futuro. Bauman ${ }^{(1)}$ afirma que uma responsabilidade crescente recai sobre os ombros dos indivíduos ao mesmo tempo em que a sociedade e as instituições que as configuram (Estado, instituições financeiras e empresariais) se inibem cada vez mais de realizar a parte que Ihes corresponde no empreendimento do atingir o estágio de humanidade plena. Sem a existência de relatos coletivos que atribuam significado à história e às vidas dos indivíduos, "surfa-se nas ondas" de uma sociedade líquida, instável, individualizada e imprevisível.

Ser pessoa por si só já constitui uma questão complexa e parece oportuno fazer uma síntese, do pensamento de Perestrello(2), clínico, psiquiatra psicanalista ("pai" da psicossomática no Brasil), a respeito do homem. Para esse autor, o ser humano ao nascer traz consigo um patrimônio por convenção denominado herança, transmitido através dos gens, provenientes da espécie como um todo e particularmente de seus ascendentes familiares. Também como caracteres herdados da espécie, o homem nasce com três emoções básicas: o medo (angústia), o amor (erotismo), o odio (agressividade) e com esses requisitos, mais o que adquire na vida intrauterina, ele é exposto ao mundo externo ("líquido e instável"), onde vai manter a unidade feto-mãe (que hoje talvez não tenha as mesmas características do passado). Essa configuração, ao longo do desenvolvimento do ser recém-nascido 
(mesmo mantendo uma certa constância) está sempre em modificação, assume novas feições e no decorrer do tempo, deixa suas marcas na personalidade do novo ser humano (cabe investigar como serão tais marcas na atualidade).

Segundo Perestrello ${ }^{(2)}$, o ser humano é uma pessoa única, com anatomia, fisiologia no máximo semelhante, mas nunca igual, também detentor do seu mundo e de suas próprias pautas de viver, ou conviver, de agir, reagir e de funcionar, tanto no âmbito de seus órgãos como no de sentir e de pensar; ele desenvolveu ao longo da sua evolução homeostase e imunologia próprias, portanto a sua forma de adoecer também possui uma configuração única.

Nessa perspectiva, a doença também é um modo peculiar de a pessoa se expressar em circunstâncias adversas. Esse autor instiga, ao afirmar que a doença assim como as outras manifestações do ser humano, representam um modo de existir, ou coexistir, pois entende que o ser humano coexiste na medida em que não é um sistema fechado. Ele, na sua totalidade, estabelece comunicação com o seu ambiente físico e social, que no tempo atual é um ambiente sujeito a contínuas mudanças.

Portanto, estudar, compreender a pessoa pressupõe ter amplitude para incorpora-la com o seu mundo, conhecer o passado que influenciou (em maior ou menor grau) a percepção do contexto específico presente (percebido como adverso), que pode ter mobilizado comportamentos e motivos que levaram ao adoecer atual e também, as formas que estabeleceu para lidar com o sofrimento.

O desafio de quem atende profissionalmente as necessidades do outro é voltar o seu olhar para essa pessoa, estar disponível para ouvir, ter senso de adequação ao elaborar as perguntas (sem ser invasivo ou arrogante) que identifiquem possibilidades; perguntas são um recurso que ao mesmo tempo permite ampliar o conhecimento ou sua limitação, no caso de ser dirigida a um ponto específico.

A formulação de perguntas, nas duas perspectivas, tem sua recomendação e desde que bem colocadas na estrutura da abordagem vão fornecer a base para a intervenção, que sempre deve estar em consonância com as singularidades da pessoa atendida, sem o apressamento para que ela supere sua condição de sofrimento e volte ao funcionamento "normal".

Observa-se um arrefecimento do interesse, tanto nos estudos como na prática dos serviços, sobre temas relativos à processos de intervenção baseados no apoio, na compreensão, na solidariedade, como se não existisse cientificidade nisso. Visivelmente, constata-se o reducionismo ao biológico do ser humano cliente e inclusive do ser profissional(3). Não raro o profissional refere informalmente, sentir a necessidade de adquirir informação sobre a abordagem e acolhimento emocional, de ter um suporte dessa natureza (para cuidar de si e do outro), mas não o assumir de forma expressa, numa evidente negação da importância do apoio emocional, talvez por que no seu meio profissional não se valorize, ou devido ao receio de que a ação de apoiar propicie uma intimidade que leve à perda do próprio controle e da situação vivenciada.

Essa postura, certamente tem inibido pesquisadores na busca para identificar e articular fundamentos teóricos que ajudem na formulação de ações que opontem os níveis de atuação e que na prática possam se mostrar efetivas na oferta do apoio emocional. Da mesma forma, os profissionais têm se tolhido de oferecer e avaliar a efetividade de ações referentes ao tema, considerando que essa prática compete ao especialista.

O encontro entre duas ou mais pessoas pode ser um sistema de apoio ou suporte, quando as trocas de energia são positivas e oferecem apoio instrumental ou emocional(4) e atendem as diversas necessidades.

O apoio instrumental pode ser entendido como uma das várias modalidades de ajuda: financeira, na divisão de responsabilidades, no oferecimento de informações. Já, o apoio emocional, identifica-se nas manifestações de afeição, aprovação, simpatia e preocupação para com o outro, e em ações que induzem a um sentimento de pertença ao grupo ${ }^{(4)}$.

Essas demonstrações recebidas e percebidas pelas pessoas são fundamentais para a manutenção da sua saúde mental, no enfrentamento de situações difíceis, estressantes, que implicam na mudança de papéis sociais (tornar-se mãe ou pai, aposentar-se), em perdas (pessoa querida, perda do estado de saúde original), ou incorporação de um encargo adicional (cuidar de alguém que exige esforço físico e/ou mental) à vida cotidiana. Cabe indagar, se existe disponibilidade dos profissionais para apreender como lidam, na atualidade, as pessoas com as situações novas, se estas ocorrem em contextos carentes das antigas âncoras sociais, como família próxima, vizinhança conhecida, dentre outros? Artigos presentes neste número podem dar uma perspectiva do cenário, em resposta a essa questão. 
As situações críticas significam momentos de dor e de sofrimento, mas também constituem possibilidades de amadurecimento tanto para quem as vivencia, como para aqueles que participam providenciando as formas de apoio, seja profissional ou solidário. Ser protagonista ou coadjuvante em eventos críticos promove a reflexão sobre valores e prioridades estabelecidas, abandonar antigos hábitos, descobrir novas potencialidades e interesses, enfim adquirir outras posturas frente à vida como um todo (pessoal e profissional). Isso é particularmente necessário nas sociedades atuais percebidas por alguns como hostis, posto que as instituições que conhecem e de onde vêm recebendo aportes podem não ser duradouras.

Como profissionais, é imprescindível adquirir essa compreensão e aprender a olhar a realidade do trabalho nessa perspectiva, do contrário a impotência e o tumulto tomarão lugar definitivo, seguidos do desamparo, assim como do medo de não dar conta e a dificuldade de pensar com clareza. Esse quadro específico aparece configurado por sentimentos, sensações e pensamentos e transparece com mais ou menos intensidade nos artigos aqui apresentados, através dos relatos tanto dos clientes dos serviços de saúde, de cuidadores solidários, como de profissionais que ministraram apoio durante os atendimentos.

Cabe a todos aqueles que atuam com a população incorporar a ideia de que na "modernidade líquida" não há as mesmas certezas, que a observação do contexto é imprescindível, que a contínua reflexão é uma necessidade fundamental assim como a aproximação com as vivências de indivíduos e situações, afim de estimular a solidariedade pelo outro enquanto princípio moral(5) $\mathrm{e}$ isso vale tanto para os caso dos profissionais como para cuidadores e vizinhos. É preciso mostrar aos sujeitos que os problemas emocionais podem ser resolvidos individualmente ou na companhia de pessoas solidárias, que ele não precisa ser "vítima", posto que nem toda experiência é doença passível de ser medicalizada, apesar dos incentivos para transformá-la em doença ${ }^{(4)}$. É necessário resgatar na população a crença na capacidade do ser humano para resolver problemas e em última instância, lidar com os dissabores da vida; condição imprescindível para diminuir o sentimento de vulnerabilidade que atualmente impera.

Tem-se novos consensos teóricos e ideológicos que afirmam que a diferença não só é inevitável como também positiva ${ }^{(5)}$. e então, o desafio é como viver nesse cotidiano de indivíduos e grupos diversos de múltiplas identidades, que precisam efetuar alterações para se adequar à fluidez dos tempos atuais. Maior desafio ainda é ser indivíduo e profissional cujo foco é procurar ajudar a si e a esses outros em tal contexto. Todavia não cabe o desânimo e como alento a todos os leitores, pensem que a possibilidade de vivenciar momentos diferentes e experimentar ações novas e criativas não deixa de ser instigante e promissor.

\section{Referências}

1. Bauman Z. Modernidade líquida. Rio de Janeiro: Zahar; 2001.

2. Perestrello D. A medicina da pessoa. 2.ed. Rio de Janeiro: Atheneu; 1974.

3. Bruck NRV. Primeiros auxílios psicológicos. Porto Alegre: Gênese Editora; 2009.

4. St John C, Winston TJ. The effect of social support, on prenatal care. J Appl Behav Sci. 1989; 25:79-98.

5. Béjar H. Identidades inciertas: Zigmunt Bauman. Barcelona: Herder Editorial; 2007.

Margarita Antonia Villar Luis

Editor Chefe da SMAD, Revista Eletrônica Saúde Mental Álcool e Drogas, Professor Titular da Escola de Enfermagem de Ribeirão Preto, Universidade de São Paulo, Centro Colaborador da OPAS/OMS para o Desenvolvimento da Pesquisa em Enfermagem, Brasil, e-mail: margarit@eerp.usp.br 